\title{
Physical activity and dietary habits among Moroccan adolescents
}

\author{
Abdeslam Hamrani ${ }^{1, *}$, Slimane Mehdad ${ }^{2}$, Khalid El Kari ${ }^{2}$, Asmaa El Hamdouchi $^{2}$, \\ Imane El Menchawy ${ }^{2}$, Hakim Belghiti ${ }^{3}$, Mohammed El Mzibri ${ }^{2}$, \\ Abdulrahman $\bigcirc$ Musaiger ${ }^{4}$, Hazzaa M Al-Hazzaa ${ }^{5}$, Andrew P Hills ${ }^{6}$, Najat Mokhtar ${ }^{2}$ and \\ Hassan Aguenaou ${ }^{2}$ \\ 'Université lbn Tofaill, Faculté des Sciences, Département de Biologie, Laboratoire de Nutrition et Santé, BP 133, \\ Kénitra 14000, Morocco: ${ }^{2}$ Unité Mixte de Recherche en Nutrition \& Alimentation (Université lbn Tofaïl - Centre \\ National de l'Energie, des Sciences et des Techniques Nucléaires), URAC 39, Rabat, Morocco: ${ }^{3}$ Unité de \\ Nutrition-Service d'Hygiène et Médecine de Collectivité, Hôpital Militaire d'Instruction Mohammed V, Rabat, \\ Morocco: ${ }^{4}$ Nutrition and Health Studies Unit, Deanship of Scientific Research, University of Bahrain and Arab \\ Center for Nutrition, Manama, Bahrain: ${ }^{5}$ Exercise Physiology Laboratory, Department of Physical Education and \\ Movement Science, College of Education and Scientific Board, Obesity Research Chair, King Saud University, \\ Riyadh, Saudi Arabia: 'Mater Mothers' Hospital, Mater Research and Griffith Health Institute, Griffith University, \\ Brisbane, Queensland, Australia
}

Submitted 16 August 2013: Final revision received 7 September 2014: Accepted 9 September 2014: First published online 31 October 2014

\begin{abstract}
Objective: The study aimed to detail the lifestyle (physical activity and dietary habits) of Moroccan adolescents.

Design: Cross-sectional study undertaken in the framework of the ATLS (Arab Teens Lifestyle Study).

Setting: Physical activity and dietary habits were determined using a validated questionnaire in public secondary schools.

Subjects: A total of 669 adolescents aged 15.0-19.9 years were randomly recruited from Kenitra, Morocco.

Results: Physical activity patterns and intensity differed between genders. As anticipated, male adolescents were more active than female adolescents across a typical week and engaged in more vigorous-intensity physical activity than female adolescents, who spent more time than male adolescents in moderate-intensity physical activity. Of particular concern was that one in five of the adolescents surveyed was inactive, with almost $45 \%$ of the sample reporting television viewing for more than $2 \mathrm{~h} / \mathrm{d}$ and $38 \%$ engaged in computer use for a similar period. From a dietary perspective, most adolescents reported that they do not take breakfast or consume milk and dairy products, fruits and vegetables on a daily basis. In contrast, most reported consumption of doughnuts, cakes, candy and chocolate more than three times per week and approximately $50 \%$ consumed sugary drinks more than three times per week.

Conclusions: Based on a continuation of the self-reported lifestyle behaviours, adolescents in the present study are at risk of developing chronic diseases. Education programmes are urgently needed to assist in the promotion of a healthy lifestyle and reduce the likelihood of overweight and obesity and related health risks among young people.
\end{abstract}

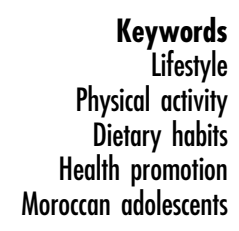

Physical activity is defined as any bodily movement produced by skeletal muscles that results in energy expenditure above basal level and regular engagement in physical activity is widely acknowledged as having important health benefits ${ }^{(1,2)}$. For example, physical activity has been described as essential for the normal growth and development of children and adolescents, in addition to its beneficial effects in reducing the risk of obesity and associated health problems such as type 2 diabetes mellitus, CVD and bone health problems ${ }^{(3-9)}$. Encouraging all children and adolescents, irrespective of their level of overweight, to increase participation in physical activity and exercise, and reduce sedentary or inactive behaviours, will help to avoid excess weight gain over time ${ }^{(10)}$. Physical activity contributes to the improvement of body composition and assists in maintenance of weight loss ${ }^{(11)}$. A recent study 
showed that physical activity plays an important role in the prevention of overweight and obesity in childhood and adolescence, and reduces the risk of obesity in adult$\operatorname{hood}^{(7)}$. Without appropriate involvement in physical activity, there is an increased likelihood that children will live less healthy lives than their parents ${ }^{(12)}$. However, particular emphasis must be placed on educating children and families affected by obesity about the range of health benefits associated with physical activity ${ }^{(13)}$ rather than simply focusing on the need for weight loss per $s e^{(14)}$.

In addition, there is increasing evidence that health behaviours cluster. For example, regular physical activity and healthy dietary habits in combination help to maintain and improve physical and mental health and wellbeing ${ }^{(15)}$. During the growing years, optimal nutrition in combination with regular physical activity increases the likelihood of a healthy pattern of physical maturation consistent with the genetic potential of an individual child $^{(6,16)}$. Physical activity and diet are the cornerstones of obesity prevention and management ${ }^{(17)}$. Moreover, obesity is further complicated by the complex interaction between diet, physical activity and metabolic and genetic factors ${ }^{(18)}$ in an environment that encourages consumption of high-energy foods and discourages expenditure of energy ${ }^{(19)}$.

Poor lifestyle practices, including the consumption of high-fat diets and low levels of physical activity, have contributed to an increase in the prevalence of overweight and obesity in adolescents ${ }^{(20,21)}$. However, the shift in disease burden in low- and middle-income countries has largely been attributed to the ongoing nutrition transition and lifestyle changes characterized by changes in food supply and intake and reduced leisure-time and occupational physical activity ${ }^{(22)}$. Physical inactivity or sedentary behaviours and unhealthy diets are considered among the leading causes of major non-communicable diseases, thus contributing substantially to the global burden of disease, death and disability ${ }^{(23)}$.

Owing to the high risk of overweight adolescents becoming obese adults, the engagement of children and adolescents in physical activity and sport is a fundamental goal of obesity prevention ${ }^{(7)}$. Thus, the aim of the present study was to describe the lifestyle (physical activity and dietary habits) of Moroccan adolescents as a forerunner to the development of a national strategy to promote physical activity and healthy eating practices, aimed to reduce obesity and related diseases.

\section{Participants and methods}

\section{Participants}

The current study was conducted in the framework of the ATLS regional project (Arab Teens Lifestyle Study), which is a school-based, cross-sectional, multi-centre collaborative study ${ }^{(24)}$. The ATLS project was coordinated by the Arab Center of Nutrition, and included Saudi Arabia, the United Arab Emirates, Bahrain, Kuwait, Iraq, Jordan, Oman, Tunisia and Morocco. The total sample comprised 669 Moroccan adolescents (325 males; 344 females) aged 15.0-19.9 years who were randomly recruited from public secondary schools of Kenitra, a city in the northern part of Morocco. The minimum required sample size was determined so that the sample proportion would be within \pm 0.05 of the population proportion with a $95 \%$ confidence interval ${ }^{(25)}$. Based on ATLS orientation for sampling, five secondary schools were randomly selected: one to the north, one to the south, one to the east and two in the centre of Kenitra. Subsequently, four classes were chosen at each secondary school: one class by level (grade 1, 2 and 3) plus another class from the largest level to reach the desired number of participants. All classes were mixed (males and females) and all participants were apparently healthy with no physical disabilities. Measurements were completed in the morning and in a private site of examination at each secondary school. The consent of each participant, the authorization and the required ethical approval of the National Ministry of Education were obtained.

\section{Anthropometry}

Body weight, height, waist circumference, BMI and body surface area were determined ${ }^{(26)}$. Body weight was measured to the nearest $100 \mathrm{~g}$ using a calibrated portable scale (Seca 750, Germany; $150 \pm 0 \cdot 1 \mathrm{~kg}$ ). Participants were wearing minimal clothing and barefoot. Height was measured to the nearest $1 \mathrm{~mm}$ using a stadiometer (Seca, Germany; $200 \pm 0 \cdot 1 \mathrm{~cm}$ ). Waist circumference was horizontally measured to the nearest $0 \cdot 1 \mathrm{~cm}$ using a non-stretchable measuring tape at the level of the umbilicus, with the tape snug but without the skin being compressed. BMI was calculated as a ratio of weight $(\mathrm{kg})$ to height squared $\left(\mathrm{m}^{2}\right)$. Body surface area was calculated using the DuBois formula ${ }^{(27)}$ : Body surface area $=0.007184 \times$ body weight $(\mathrm{kg})^{0.425} \times$ height $(\mathrm{cm})^{0.725}$. BMI-for-age was used to determine obesity $(Z$-score $>+2)$, overweight $(Z$-score $>+1)$ and normal weight $(Z$-score $=-2$ to +1 ) according to the growth standards published by the WHO in 2007 for children and adolescents.

\section{Physical activity}

The ATLS lifestyle questionnaire consists of forty-seven items, including items for the assessment of physical activity and inactivity. The physical activity questionnaire was modified from an earlier instrument previously shown to have acceptable reliability and fair validity against a pedometer in $15-25$-year-old males ${ }^{(28,29)}$. Recently, the ATLS questionnaire was also validated against an electronic pedometer in males and females (mean age 16.1 (SD 1.1) years) with mean step counts of 6866 (sD 3854) steps/d with no significant gender difference ${ }^{(30)}$. Participants completed the questionnaire in a classroom setting and supervised by school and research project staff in March 2011. 
The physical activity questionnaire collects complete information on frequency, duration and intensity of light-, moderate- and vigorous-intensity physical activities during a typical week and includes domains such as transport, household, fitness and sports activities.

Moderate-intensity activities include normal-pace walking, brisk walking, recreational swimming, household activities and sports such as volleyball, badminton and table tennis. Moderate-intensity activities were assigned MET (metabolic equivalent of task) values based on the compendium of physical activities ${ }^{(31)}$ and the compendium of physical activities for youth $^{(32)}$. Moderate-intensity recreational sports were assigned an average MET value equivalent to 4 MET. Slow walking, normal-pace walking and brisk walking were assigned MET values of $2.8,3.5$ and 4.5 MET, respectively, based on modified MET values from the compendium for youth ${ }^{(32)}$.

Vigorous-intensity physical activity and sports included stair climbing, jogging, running, bicycling, self-defence, weight training and soccer, basketball, handball and singles tennis. Such sports were assigned an average value of 8 MET.

Energy expenditure in MET-min/week was computed from intensity, duration and frequency of activity; participants were subsequently categorized into physically active or inactive based on total physical activity cut-off scores of $1680 \mathrm{MET}-\mathrm{min} /$ week $(60 \mathrm{~min} / \mathrm{d} \times 7 \mathrm{~d} /$ week $\times 4 \mathrm{MET})$, corresponding to $1 \mathrm{~h}$ of daily moderate-intensity physical $\operatorname{activity}^{(25)}$.

\section{Sedentary activity}

The ATLS questionnaire also included some items regarding daily time spent watching television and using a computer. The maximal time spent on sedentary activities (television viewing and computer use) was used to classify the study population into two categories: $\leq 2$ and $>2 \mathrm{~h} / \mathrm{d}$. Two hours per day is the recommended duration defined by the American Academy of Pediatrics ${ }^{(33)}$.

\section{Assessment of dietary habits}

Dietary habits were categorized into two groups: (i) healthy habits such as taking breakfast, consumption of vegetables (cooked and uncooked), fruits, milk and dairy products; and (ii) unhealthy habits such as consumption of sugary drinks, doughnuts/cakes, sweets (candy and chocolate), plus energy drinks and fast foods.

\section{Statistical analysis}

All analyses were undertaken using the statistical software package IBM SPSS Statistics version 17.0 and Microsoft ${ }^{\circledR}$ Office Excel version 2007. Data were presented as medians and interquartile ranges (25th-75th percentile), percentages and $95 \%$ confidence intervals. The normality of the distribution was tested by the KolmogorovSmirnov test. The $95 \%$ confidence interval values were determined using the bootstrap technique based on 1000 bootstrap samples. The $\chi^{2}$ test or Fisher's test was used to test associations between nominal variables; the Mann-Whitney $U$ test to compare medians between two independent samples. Logistic regression analysis was used to determine odds ratios and test crude associations of lifestyle habits with overweight and obesity in male and female adolescents. The normal weight group was considered as a reference category. $P$ values $<0.05$ were considered significant. Concerning data cleaning and to avoid over-reporting, physical activity scores were cleaned and truncated at reasonable and realistic levels. For example, reported time for each vigorous-intensity physical activity was truncated at $120 \mathrm{~min} / \mathrm{d}$, while time spent on household activity was truncated at $180 \mathrm{~min} / \mathrm{d}$. In addition, the maximum number of stair levels taken by a participant per day was capped at thirty floors (i.e. ten floors, three times daily). Finally, the maximal time spent on physical activity per week was truncated at $1680 \mathrm{~min}(28 \mathrm{~h})$, or $4 \mathrm{~h}$ of physical activity per day. Syntax statements were written to compute activity energy expenditure.

\section{Results}

The age and anthropometric characteristics of the participants are presented in Table 1 . We noted a significantly higher body weight, height and body surface area among male adolescents while BMI was higher among female adolescents.

The physical activity profile of the participants is shown in Table 2, and the time and energy expenditure data are presented in Table 3.

Physical activity patterns and intensity differed between genders. As anticipated, male adolescents were more active than female adolescents across a typical week and engaged in more vigorous-intensity physical activity than female adolescents, who spent more time in moderateintensity physical activity. Male adolescents engaged in sport activities in a range of settings - at school, in sports clubs and in the street - whereas female adolescents preferred to practise sport at school. Of particular concern was that one in five of the adolescents surveyed was inactive, with almost $45 \%$ of the sample reporting television viewing for more than $2 \mathrm{~h} / \mathrm{d}$ and $38 \%$ engaged in computer use for a similar period (see Figs 1 and 2).

The profile of dietary habits is shown in Table 4. Most adolescents reported eating no breakfast and failing to consume milk and dairy products, fruits and vegetables on a daily basis. In contrast, most reported consumption of doughnuts, cakes, candy and chocolate more than three times per week and approximately $50 \%$ consumed sugary drinks more than three times per week.

Supplemental Table 1 (see online supplementary material) illustrates crude associations of lifestyle habits with overweight and obesity in adolescents. The table shows that inactive females had over four times the risk $(\mathrm{OR}=4 \cdot 23$; 
Table 1 Descriptive characteristics of the participants: Moroccan adolescents aged 15.0-19.9 years, ATLS (Arab Teens Lifestyle Study), March 2011

\begin{tabular}{|c|c|c|c|c|c|c|c|}
\hline & \multicolumn{2}{|c|}{ All (n 669) } & \multicolumn{2}{|c|}{ Males (n 325) } & \multicolumn{2}{|c|}{ Females (n 344) } & \multirow[b]{2}{*}{$P$ value } \\
\hline & Median & IQR & Median & IQR & Median & IQR & \\
\hline Age (years) & $17 \cdot 0$ & $16 \cdot 0-18 \cdot 0$ & $17 \cdot 0$ & $16 \cdot 0-18 \cdot 0$ & $17 \cdot 0$ & $16 \cdot 0-18 \cdot 0$ & 0.372 \\
\hline Body weight (kg) & $55 \cdot 0$ & $50 \cdot 0-62 \cdot 3$ & $58 \cdot 0$ & $53 \cdot 0-65.0$ & 52.5 & $48 \cdot 0-58.4$ & 0.000 \\
\hline Height $(\mathrm{cm})$ & $166 \cdot 2$ & $16 \cdot 3-173 \cdot 4$ & $173 \cdot 4$ & $168 \cdot 5-177 \cdot 6$ & $160 \cdot 9$ & $157 \cdot 5-165 \cdot 0$ & 0.000 \\
\hline Waist circumference (cm) & $72 \cdot 0$ & $68 \cdot 0-77 \cdot 2$ & $72 \cdot 0$ & $69 \cdot 0-77 \cdot 0$ & $72 \cdot 0$ & $67 \cdot 0-78 \cdot 0$ & 0.306 \\
\hline Body surface area $\left(\mathrm{m}^{2}\right)$ & $1 \cdot 6$ & $1 \cdot 5-1 \cdot 7$ & $1 \cdot 7$ & $1 \cdot 6-1 \cdot 8$ & 1.5 & $1.5-1.6$ & 0.000 \\
\hline $\mathrm{BMI}\left(\mathrm{kg} / \mathrm{m}^{2}\right)$ & $19 \cdot 7$ & $18 \cdot 3-21 \cdot 8$ & $19 \cdot 4$ & $18 \cdot 0-21 \cdot 2$ & $20 \cdot 3$ & $18 \cdot 7-22 \cdot 4$ & 0.000 \\
\hline
\end{tabular}

IQR, interquartile range (25th-75th percentile).

*The Mann-Whitney $U$ test was used to compare medians between males and females.

Table 2 Physical activity profiles of the participants: Moroccan adolescents aged 15.0-19.9 years, ATLS (Arab Teens Lifestyle Study), March 2011

\begin{tabular}{|c|c|c|c|c|c|}
\hline & All (n 669) & $95 \% \mathrm{Cl}^{*}$ & Males (n 325) & Females (n 344) & $P$ value \\
\hline \multicolumn{6}{|l|}{ Place } \\
\hline Home & 11.66 & $9.27,14.05$ & 7.08 & 15.99 & 0.000 \\
\hline School & $47 \cdot 23$ & $43 \cdot 65,51 \cdot 12$ & $26 \cdot 46$ & $66 \cdot 86$ & \\
\hline Streets or squares & $18 \cdot 39$ & $15.55,21.52$ & $26 \cdot 77$ & $10 \cdot 47$ & \\
\hline Sports clubs & $15 \cdot 10$ & $12.41,17.94$ & $27 \cdot 38$ & 3.49 & \\
\hline Others & $7 \cdot 62$ & $5.68,9.86$ & $12 \cdot 31$ & $3 \cdot 20$ & \\
\hline \multicolumn{6}{|l|}{ Playmate } \\
\hline None & $6 \cdot 28$ & $4.49,8 \cdot 22$ & $5 \cdot 23$ & $7 \cdot 27$ & 0.000 \\
\hline Friends & $47 \cdot 53$ & $43 \cdot 65,51 \cdot 27$ & $69 \cdot 54$ & $26 \cdot 74$ & \\
\hline Relatives & 3.74 & $2 \cdot 39,5 \cdot 23$ & 3.38 & $4 \cdot 07$ & \\
\hline Classmates & $37 \cdot 07$ & $33.48,40 \cdot 80$ & $18 \cdot 15$ & 54.94 & \\
\hline Parents & $2 \cdot 39$ & $1 \cdot 35,3.59$ & 0.92 & 3.78 & \\
\hline Others & 2.99 & $1 \cdot 79,4 \cdot 19$ & 2.77 & $3 \cdot 20$ & \\
\hline \multicolumn{6}{|l|}{ Period } \\
\hline Morning & $54 \cdot 86$ & $51 \cdot 27,58.59$ & 43.08 & 65.99 & 0.000 \\
\hline Afternoon & $7 \cdot 62$ & $5 \cdot 68,9.87$ & 11.08 & $4 \cdot 36$ & \\
\hline Evening & $7 \cdot 17$ & $5 \cdot 23,9.27$ & $10 \cdot 46$ & 4.07 & \\
\hline After sunset & $6 \cdot 43$ & $4.63,8.37$ & $11 \cdot 38$ & $1 \cdot 74$ & \\
\hline After dinner & 1.94 & $1 \cdot 05,3 \cdot 14$ & $3 \cdot 38$ & 0.58 & \\
\hline There is no specific time & 21.97 & $18 \cdot 98,25 \cdot 11$ & $20 \cdot 62$ & $23 \cdot 26$ & \\
\hline
\end{tabular}

Results are presented as proportions (\%).

*Bootstrap results for the total proportions were based on 1000 bootstrap samples.

tThe $X^{2}$ test was used to determine $P$ values between nominal variables.

Table 3 Time spent on physical and sedentary activities and energy expenditure among Moroccan adolescents aged 15.0-19.9 years, ATLS (Arab Teens Lifestyle Study), March 2011

\begin{tabular}{|c|c|c|c|c|c|}
\hline & \multicolumn{2}{|c|}{ Males ( $n$ 325) } & \multicolumn{3}{|c|}{ Females ( $n$ 344) } \\
\hline & Median & IQR & Median & IQR & $P$ value ${ }^{\star}$ \\
\hline \multicolumn{6}{|l|}{ Duration (h/week) } \\
\hline Total physical activity & $11 \cdot 2$ & $7 \cdot 6-17 \cdot 0$ & $8 \cdot 1$ & $5 \cdot 0-12 \cdot 7$ & 0.000 \\
\hline Moderate physical activity & $3 \cdot 3$ & $2 \cdot 0-5 \cdot 3$ & $5 \cdot 8$ & $3 \cdot 3-10 \cdot 3$ & 0.000 \\
\hline Vigorous physical activity & $6 \cdot 8$ & $4 \cdot 0-11 \cdot 1$ & 1.7 & $0.9-2.5$ & 0.000 \\
\hline Sedentary activity (television viewing and computer use) & 4.5 & $3.0-6.5$ & 4.5 & $2 \cdot 6-6.5$ & 0.702 \\
\hline \multicolumn{6}{|l|}{ Energy expenditure (MET-min/week) } \\
\hline Total physical activity & $4064 \cdot 7$ & $2708 \cdot 8-6268 \cdot 3$ & 2183.9 & $1429 \cdot 1-3197 \cdot 0$ & 0.000 \\
\hline Moderate physical activity & $705 \cdot 0$ & $432 \cdot 0-1225 \cdot 0$ & $1200 \cdot 0$ & $675 \cdot 0-1990 \cdot 0$ & 0.000 \\
\hline Vigorous physical activity & $3194 \cdot 7$ & $1903 \cdot 3-5159 \cdot 7$ & $811 \cdot 6$ & $437 \cdot 3-1212 \cdot 3$ & 0.000 \\
\hline
\end{tabular}

IQR, interquartile range (25th-75th percentile); MET, metabolic equivalent of task.

*The Mann-Whitney $U$ test was used to compare medians between males and females.

$95 \%$ CI $1 \cdot 04,17 \cdot 28)$ to be obese than active females. Male adolescents who used a computer for more than $2 \mathrm{~h} / \mathrm{d}$ had almost four times (OR $=3.78$; $95 \%$ CI $1.43,10 \cdot 02)$ the risk to be overweight than their counterparts who used a computer for $2 \mathrm{~h} / \mathrm{d}$ or less. Adolescents who did not consume breakfast at home on a daily basis were at increased risk to be overweight compared with those who had daily breakfast consumption: risk increased about threefold for males 


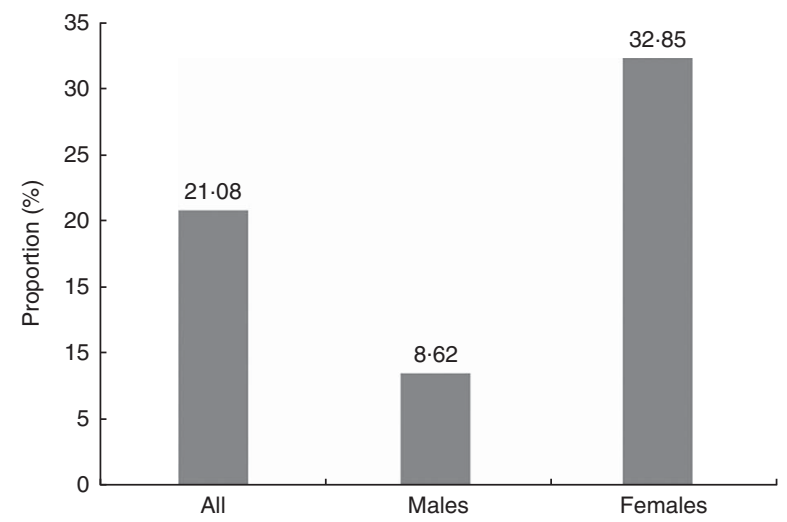

Fig. 1 Levels of physical inactivity (defined as energy expenditure value $<1680 \mathrm{MET}$-min/week, where MET is metabolic equivalent of task) among Moroccan adolescents ( $n 669 ; 325$ males and 344 females) aged 15.0-19.9 years, ATLS (Arab Teens Lifestyle Study), March 2011. A greater percentage of females were physically inactive compared with males $(P=0.000)$

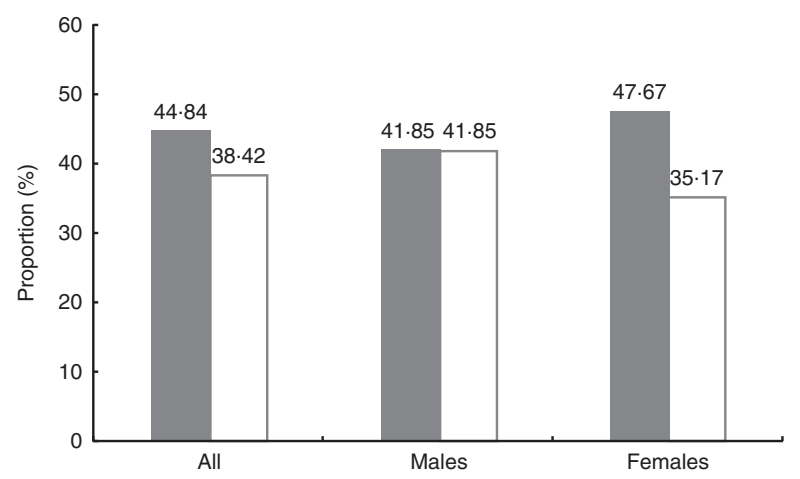

Fig. 2 Levels of sedentary activities (defined as duration $>2 \mathrm{~h} / \mathrm{d}$; , television viewing; $\square$, computer use) among Moroccan adolescents ( $n$ 669; 325 males and 344 females) aged 15.019.9 years, ATLS (Arab Teens Lifestyle Study), March 2011. Television viewing for $>2 \mathrm{~h} / \mathrm{d}$ did not vary between males and females $(P=0.140)$; computer use for $>2 \mathrm{~h} / \mathrm{d}$ did not vary between males and females $(P=0.081)$
$(\mathrm{OR}=2.76 ; 95 \% \mathrm{CI} 1.04,7.32)$ and about fourfold for females (OR $=3.70 ; 95 \%$ CI 1.28, 10.73). Moreover, female adolescents who consumed sugary drinks more than three times weekly had more than twice at risk to be overweight $(\mathrm{OR}=2 \cdot 48 ; 95 \% \mathrm{CI} 1.24,4.96)$ compared with their counterparts who consumed sugary drinks less often.

\section{Discussion}

The present study is the first of its kind to describe the lifestyle (physical activity and dietary habits) of Moroccan adolescents. Major findings included a large proportion of adolescents who reported unhealthy dietary practices including skipping breakfast and making less healthy food choices in a typical week. This was coupled with inadequate levels of physical activity in many adolescents and high levels of inactivity or sedentary behaviours.

Interventions that promote a healthy and active lifestyle play an important role in the prevention and management of overweight and obesity in this population, particularly school-based interventions ${ }^{(34,35)}$. The present study showed that most female adolescents (67\%) engaged in physical activity at school with classmates, while $27 \%$ of male adolescents practised physical activity with friends at school, in the street and at sports clubs. Based on the time spent at school, this setting seems to be the most practical as well as the most common place to participate in physical activity. Respondents also confirmed that the preferred time of day for physical activity was during the morning.

Results of the present study indicated some differences between genders in size and shape measures, including higher height, weight and body surface area values in male adolescents and higher BMI among female adolescents. The higher BMI among female adolescents is consistent with the high proportion of physical inactivity reported (more evident findings in Supplemental Table 1), the lower time

Table 4 Dietary habit profiles of the participants: Moroccan adolescents aged 15.0-19.9 years, ATLS (Arab Teens Lifestyle Study), March 2011

\begin{tabular}{|c|c|c|c|c|c|}
\hline & All $(n$ 669) & $95 \% \mathrm{Cl}^{*}$ & Males ( $n$ 325) & Females (n 344) & $P$ value† \\
\hline \multicolumn{6}{|l|}{ Healthy dietary habits ( $\geq 7$ times/week) } \\
\hline Breakfast at home & 38.86 & $35 \cdot 13,42.45$ & $50 \cdot 77$ & 27.62 & 0.000 \\
\hline Vegetables & 49.18 & $45 \cdot 29,52 \cdot 77$ & 47.69 & 50.58 & 0.455 \\
\hline Fruits & 27.80 & $24 \cdot 07,30 \cdot 79$ & 24.92 & 30.52 & 0.106 \\
\hline Milk or dairy products & 38.12 & $34 \cdot 38,41 \cdot 70$ & 37.54 & 38.66 & 0.765 \\
\hline \multicolumn{6}{|l|}{ Unhealthy dietary habits (>3 times/week) } \\
\hline Fast foods & 19.58 & $16 \cdot 74,22 \cdot 42$ & $16 \cdot 31$ & $22 \cdot 67$ & 0.038 \\
\hline Fried potatoes (French fries and chips) & 35.13 & $31 \cdot 24,38 \cdot 71$ & $27 \cdot 38$ & 42.44 & 0.000 \\
\hline Doughnuts/cakes & $65 \cdot 17$ & $61.29,68.46$ & 53.85 & $75 \cdot 87$ & 0.000 \\
\hline Candy/chocolate & 62.03 & $58 \cdot 30,65 \cdot 92$ & 54.77 & 68.90 & 0.000 \\
\hline Sugary drinks & 45.44 & $41 \cdot 70,49 \cdot 18$ & $46 \cdot 77$ & 44.19 & 0.502 \\
\hline Energy drinksł & 3.89 & $2.54,5.38$ & $5 \cdot 23$ & 2.62 & 0.080 \\
\hline
\end{tabular}

Results are presented as proportions (\%).

${ }^{*}$ Bootstrap results for the total proportions were based on 1000 bootstrap samples.

†The $X^{2}$ test or Fisher's test was used to determine $P$ values between nominal variables.

†Energy drinks: Red Bull, Power Horse or others. 
and energy expenditure associated with vigorous-intensity physical activity, and also physiological factors. Low levels of habitual physical activity and insufficient vigorousintensity activity have been reported as risk factors for higher BMI in this population ${ }^{(36)}$. Moroccan female adolescents do not spend enough time engaged in vigorousintensity physical activity and also only expended approximately half the energy of male adolescents in physical activity. A combination of optimal nutrition and regular physical activity during a child's formative years increases the likelihood of a healthy pattern of physical maturation consistent with genetic potential $^{(6,37)}$.

Similarly, previous studies have shown that children and adolescents who participate in higher levels of physical activity are less likely to display risk factors for $\mathrm{CVD}^{(4,38)}$ and are more likely to have positive outcomes in weight regulation $^{(39,40)}$. As a group, one in five Moroccan adolescents was categorized as inactive; or $33 \%$ of female adolescents $v .9 \%$ of male adolescents. The prevalence of physical inactivity among Moroccan female adolescents is higher than reported in other countries ${ }^{(41)}$ such as Finland (16\%), Australia (27\%) and the USA (31\%). Worldwide, physical inactivity contributes to nearly two million deaths ${ }^{(15)}$.

Our results showed that nearly $45 \%$ of adolescents spend more than $2 \mathrm{~h} / \mathrm{d}$ in television viewing, and $38 \%$ engaged in computer use for a similar period. Such adolescents may be at greater risk of developing obesity and related diseases, particularly if physical activity levels are also low. A previous study showed that children who watch television for $1 \mathrm{~h} / \mathrm{d}$ or less have a lower prevalence of obesity ${ }^{(42)}$. However, the television viewing time among Moroccan adolescents is lower than reported in a national survey in the USA, which revealed that $65 \%$ to $67 \%$ of adolescents watched television for more than $2 \mathrm{~h} / \mathrm{d}^{(43)}$, and higher than reported in Chinese adolescents $(24 \%)^{(44)}$. In summary, today's young people spend more time than previous generations did in sedentary pursuits, including television viewing and computer use ${ }^{(14)}$.

Breakfast consumption is associated with a variety of positive outcomes, including improved daily nutrient intake profiles $^{(45,46)}$, a healthy body weight ${ }^{(47,48)}$, and better cognitive functioning and school performance ${ }^{(49)}$. However, $60 \%$ of the adolescents in the present study reported not taking breakfast on a daily basis.

Similarly, dairy products (milk, yoghurt and cheese) are a very important source of Ca during childhood, adolescence and the third age ${ }^{(50)}$, yet most of the present cohort did not consume milk and dairy products on a daily basis, nor consume fruits and vegetables on a daily basis ${ }^{(15)}$. Adult studies have shown that prudent dietary patterns high in fruits and vegetables are associated with low prevalence of the metabolic syndrome ${ }^{51,52)}$. Unfortunately, only $28 \%$ and $49 \%$ of our study population consumed fruits and vegetables respectively on a daily basis rather than the recommendation of at least five times per day ${ }^{(50)}$ as a protective factor against obesity, diabetes, CVD and cancers.
In summary, most adolescents in the present study reported unhealthy dietary habits, including the consumption of foods such as doughnuts, cakes, biscuits, sweets and chocolate and sugary drinks more than three times weekly. These practices are consistent with many parts of the world where the 'normal' diet is becoming increasingly energydense and sweeter, with high-fibre foods being replaced by more highly processed versions ${ }^{(22)}$. A continuation of such poor dietary practices increases the risk of adolescents to develop non-communicable diseases as unhealthy eating is considered one of the main causes ${ }^{(23)}$.

More interventions promoting sound nutritional practices and increased physical activity are needed in Morocco to reduce physical inactivity and sedentary behaviours and limit the intake of unhealthy foods contributing to overweight and obesity and related complications. There is very strong evidence of the effectiveness of such approaches. For example, a project in Finland reported a reduction in the burden of CVD by $70 \%$ through the promotion of good nutrition and physical activity, as well as the implementation of food policies ${ }^{(53)}$.

A recognized limitation of the present study was the inability to sample from the private education sector, mainly due to the small number of private institutions in Kenitra. However, available statistical information verified that only $6.89 \%$ of secondary-school students in the city are enrolled in private schools.

\section{Conclusion}

In conclusion, the present study described, for the first time, the lifestyle habits of a sample of Moroccan adolescents. From both a dietary and physical activity perspective, the habits of the adolescents surveyed were not consistent with a healthy lifestyle and the prevention of non-communicable diseases in adulthood. A concerted effort on the part of all relevant government agencies will be needed to develop school- and community-based interventions, and to promote physical activity and healthy eating practices among Moroccan children and adolescents. Future large-scale studies involving nationally representative samples of adolescents are recommended. Further work is also recommended to validate the self-report physical activity instrument against a gold standard reference approach such as the doubly labelled water technique.

\section{Acknowledgements}

Acknowledgements: The authors wish to thank the volunteers who participated in the study and all persons who aided to make it successful. Their sincere acknowledgement is extended to the Arab Center of Nutrition. Financial support: This research received a specific grant from the Arab Center of Nutrition. The funder has contributed in design, collaboration and data centralization of all Arab cross-sectional studies. Conflict of interest: None. 
Authorship: A.H. and S.M. participated in the collection, analysis and interpretation of the data, laboratory analysis and drafting the article. K.E.K., A.E.H., I.E.M., H.B. and M.E.M. participated in the collection of data, laboratory analysis, revising the article and final approval of the version to be submitted. A.O.M. and H.M.A.-H. were the principal coordinators in the Arab Center of Nutrition, they contributed to all the Arab studies undertaken in the framework of the ATLS project. A.P.H. revised the content on physical activity and sedentary behaviours, and made language corrections on the final version of the manuscript. N.M. and H.A. were the principal investigators of the project from which these data were derived. Ethics of human subject participation: The required ethical approval of the National Ministry of Education was obtained.

\section{Supplementary material}

To view supplementary material for this article, please visit http://dx.doi.org/10.1017/S1368980014002274

\section{References}

1. Caspersen C, Powell K \& Christenson G (1985) Physical activity, exercise, and physical fitness: definitions and distinctions for health related research. Public Health Rep $\mathbf{1 0 0}$, 126-131.

2. US Department of Health and Human Services (1996) Physical Activity and Health: A Report of the Surgeon General. Atlanta, GA: Centers for Disease Control and Prevention, National Centers for Chronic Disease Prevention and Health Promotion.

3. Hills AP (1995) Physical activity and movement in children: consequences for growth and development. Asia Pac J Clin Nutr 4, 43-45.

4. Strong WB, Malina RM, Blimkie CJR et al. (2005) Evidence based physical activity for school-age youth. J Pediatr 146 , 732-737.

5. Ekelund U, Brage S, Froberg K et al. (2006) TV viewing and physical activity are independently associated with metabolic risk in children: the European Youth Heart Study. PLoS Med 3, e488.

6. Hills AP, King NA \& Armstrong TP (2007) The contribution of physical activity and sedentary behaviours to the growth and development of children and adolescents: implications for overweight and obesity. Sports Med 37, 533-545.

7. Hills AP, Andersen LB \& Byrne NM (2011) Physical activity and obesity in children. BrJ Sports Med 45, 866-870.

8. Andersen LB, Riddoch C, Kriemler S et al. (2011) Physical activity and cardiovascular risk factors in children. $\mathrm{Br} J$ Sports Med 45, 871-876.

9. Hills AP, Street SJ, Soan E et al. (2013) Physical activity and development and obesity. Curr Obes Rep 2, 261-266.

10. Hamilton MT, Hamilton DG \& Zderic TW (2007) Role of low energy expenditure and sitting in obesity, metabolic syndrome, type 2 diabetes, and cardiovascular disease. Diabetes 56, 2655-2667.

11. Jakicic JM (2009) The effect of physical activity on body weight. Obesity (Silver Spring) 17, Suppl. 3, S34-S38.

12. Olshansky SJ, Passaro DJ, Hershow RC et al. (2005) A potential decline in life expectancy in the United States in the 21st century. $N$ Engl J Med 352, 1138-1345.
13. Daley AJ, Copeland RJ, Wright NP et al. (2008) 'I can actually exercise if I want to; it isn't as hard as I thought': a qualitative study of the experiences and views of obese adolescents participating in an exercise therapy intervention. J Health Psychol 13, 810-819.

14. Hills AP, Okely AD \& Baur LA (2010) Addressing childhood obesity through increased physical activity. Nat Rev Endocrinol 6, 543-549.

15. World Health Organization (2002) The World Health Report 2002. Reducing Risks, Promoting Healthy Life. Geneva: WHO.

16. Sallis JF \& Glanz K (2009) Physical activity and food environments: solutions to the obesity epidemic. Milbank $Q \mathbf{8 7}$, 123-154.

17. Hills AP \& Byrne NM (2006) State of the science: a focus on physical activity. Asia Pac J Clin Nutr 15, Suppl, 40-48.

18. Pietrobelli A, Malavolti M, Battistini NC et al. (2008) Metabolic syndrome: a child is not a small adult. Int J Pediatr Obes 3, Suppl. 1, 67-71.

19. Bouchard $C$ (2010) Defining the genetic architecture of the predisposition to obesity: a challenging but not insurmountable task. Am J Clin Nutr 91, 5-6.

20. Aronne LJ (2002) Obesity as a disease: etiology, treatment, and management considerations for the obese patient. Obes Res 10, Suppl. 2, 95S-96S.

21. Lobstein T, Baur L \& Uauy R (2004) Obesity in children and young people: a crisis in public health. Obes Rev 5, 4-85.

22. Popkin BM (2006) Global nutrition dynamics: the world is shifting rapidly toward a diet linked with noncommunicable diseases. Am J Clin Nutr 84, 289-298.

23. Khatib O (2004) Noncommunicable diseases: risk factors and regional strategies for prevention and care. East Mediterr Health J 10, 778-788.

24. Al-Hazzaa HM, Musaiger A \& Group ATLS (2010) Physical activity patterns and eating habits of adolescents living in major Arab cities: The Arab Teens Lifestyle Study. Saudi Med J 31, 210-211.

25. Al-Hazzaa HM \& Musaiger AO, ATLS Research Group (2011) Arab Teens Lifestyle Study (ATLS): objectives, design, methodology and implications. Diabetes Metab Syndr Obes 4, 417-426.

26. Lohman TG, Roche AF \& Martorell R (1988) Anthropometric Standardization Reference Manual. Champaign, IL: Human Kinetics.

27. DuBois D \& DuBois EF (1916) A formula to estimate the approximate surface area if height and weight be known. Arch Intern Med 17, 863-871.

28. Al-Hazzaa HM \& Al-Ahmadi M (2003) A self-reported questionnaire for the assessment of physical activity in youth 15-25 years: development, reliability and construct validity. Arab J Food Nutr 4, 279-291.

29. Al-Ahmadi M \& Al-Hazzaa HM (2004) Validity of a selfreported questionnaire for youth 15-25 years: comparison with accelerometer, pedometer and heart rate telemetry. Saudi Sports Med J 7, 2-14.

30. Al-Hazzaa HM, Al-Sobayel HI \& Musaiger AO (2011) Convergent validity of the Arab Teens Lifestyle Study (ATLS) physical activity questionnaire. Int J Environ Res Public Health 8, 3810-3820.

31. Ainsworth B, Haskell W, Whitt M et al. (2000) Compendium of physical activity: an update of activity codes and MET intensities. Med Sci Sports Exerc 32, 9 Suppl., S498-S516.

32. Ridley K, Ainsworth B \& Olds T (2008) Development of a compendium of energy expenditure for youth. Int J Behav Nutr Phys Act 5, 45.

33. American Academy of Pediatrics, Committee on Public Education (2001) American Academy of Pediatrics: Children, adolescents, and television. Pediatrics 107, 423-426.

34. Gortmaker S, Peterson K, Wiecha J et al. (1999) Reducing obesity via a school-based interdisciplinary intervention 
among youth: Planet Health. Arch Pediatr Adolesc Med 153 , 409-418.

35. Muller M, Danielzik S \& Pust S (2005) School- and familybased interventions to prevent overweight in children. Proc Nutr Soc 64, 249-254.

36. Patrick K, Norman G, Calfas K et al. (2004) Diet, physical activity and sedentary behaviors as risk factors for overweight in adolescence. Arch Pediatr Adolesc Med 158, 385-390.

37. Malina RM \& Little BB (2008) Physical activity: the present in the context of the past. Am J Hum Biol 20, 373-391.

38. Boreham C \& Riddoch C (2001) The physical activity, fitness and health of children. J Sports Sci 19, 915-929.

39. Gutin B, Barbeau P, Owens S et al. (2002) Effects of exercise intensity on cardiovascular fitness, total body composition, and visceral adiposity of obese adolescents. Am J Clin Nutr 75, 818-826.

40. Lemura LM \& Maziekas MT (2002) Factors that alter body fat, body mass, and fat-free mass in pediatric obesity. Med Sci Sports Exerc 34, 487-496.

41. Caspersen C, Merritt R \& Stephens T (1994) International physical activity patterns: a methodological perspective. In Advances in Exercise Adberence, pp. 73-110 [R Dishman, editor]. Champaign, IL: Human Kinetics.

42. Crespo CJ, Smit E, Troiano RP et al. (2001) Television watching, energy intake, and obesity in US children. Result from the third national health and nutrition examination survey, 1988-1994. Arch Pediatr Adolesc Med 155, $360-365$.

43. Andersen R, Crespo C, Bartlett S et al. (1998) Relationship of physical activity and television watching with body weight and level of fatness among children: results from the Third National Health and Nutrition Examination Survey. JAMA 279, 938-942.
44. Li M, Dibley MJ, Sibbritt DW et al. (2007) Physical activity and sedentary behavior in adolescents in Xi'an City, China. J Adolesc Health 41, 99-101.

45. Affenito SG, Thompson DG, Barton BA et al. (2005) Breakfast consumption by African-American and white adolescent girls correlates positively with calcium and fiber intake and negatively with body mass index. J Am Diet Assoc 105, 938-945.

46. Nicklas TA, Myers L \& Berenson GS (1994) Impact of readyto-eat cereal consumption on total dietary intake of children: the Bogalusa Heart Study. J Am Diet Assoc 94, 316-318.

47. Keski-Rahkonen A, Kaprio J, Rissanen A et al. (2003) Breakfast skipping and health-compromising behaviors in adolescents and adults. Eur J Clin Nutr 57, 842-853.

48. Siega-Riz AM, Popkin BM \& Carson T (1998) Trends in breakfast consumption for children in the United States from 1965-1991. Am J Clin Nutr 67, issue 4, 748S-756S.

49. Rampersaud GC, Pereira MA, Girard BL et al. (2005) Breakfast habits, nutritional status, body weight, and academic performance in children and adolescents. $\mathrm{J} \mathrm{Am}$ Diet Assoc 105, 743-760.

50. Programme National Nutrition-Santé (2002) La santé vient en mangeant. Le guide alimentaire pour tous, neuvième impression. Saint-Yrieix-la-Perche, France: Fabrègue.

51. Williams D, Prevost A, Whichelow M et al. (2000) A crosssectional study of dietary patterns with glucose intolerance and other features of the metabolic syndrome. BrJ Nutr $\mathbf{8 3}$, 257-266.

52. Pereira MA, Jacobs DR Jr, Van Horn L et al. (2002) Dairy consumption, obesity, and the insulin resistance syndrome in young adults: the CARDIA Study. JAMA 287, 2081-2089.

53. Puska P, Pirjo P \& Ulla U (2002) Influencing public nutrition for noncommunicable disease prevention. From community intervention to national programme - experiences from Finland. Public Health Nutr 5, 245-251. 